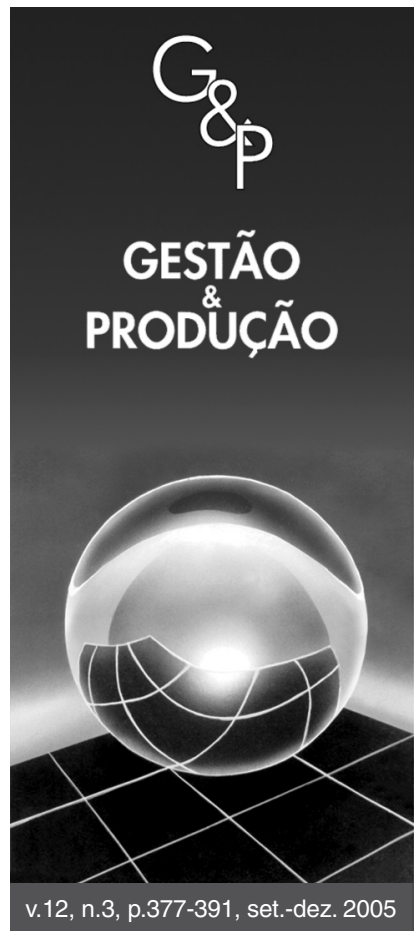

\title{
INTER-RELAÇÕES ENTRE ESTRATÉGIA DE OPERAÇÕES E GESTÃO DA CADEIA DE SUPRIMENTOS: ESTUDOS DE CASO NO SEGMENTO DE MOTORES PARA AUTOMÓVEIS
}

\author{
Jonas Lucio Maia \\ Aline Lamon Cerra \\ Alceu Gomes Alves Filho
}

Grupo de Estudos sobre a Indústria Automobilística, Departamento de Engenharia de Produção, Universidade Federal de São Carlos, Rod. Washington Luiz, Km 235, CEP 13565-905, São Carlos, SP, Brasil, e-mail: jonasmaia@ dep.ufscar.br, alinelc@terra.com.br, alceu@ power.ufscar.br

Resumo

A Indústria Automobilística no Brasil e no mundo tem passado por um processo de importantes transformações. Especificamente no Brasil, a instalação de novas montadoras, a consolidação e desnacionalização das autopeças e fenômenos como a introdução de motores de baixa cilindrada têm trazido implicações estratégicas importantes para as empresas, assim como para suas cadeias de suprimentos. Considerando estas implicações, este trabalho tem por objetivo compreender os inter-relacionamentos entre a Estratégia de Operações (EO) e a Gestão da Cadeia de Suprimentos (GCS), analisando estudos de caso em duas montadoras de motores instaladas no Brasil e dois de seus fornecedores. Os resultados indicam forte inter-relacionamento entre as prioridades competitivas e decisões nas áreas estruturais e infra-estruturais das empresas, bem como entre os aspectos estruturais e relacionais das cadeias nas quais estas estão inseridas. As montadoras estudadas apresentam EOs semelhantes, mas suas prioridades e ações ocorrem no contexto de diferentes estruturas de cadeias de suprimentos e, conseqüentemente, por meio de diferentes formas de relacionamento. Dada a influência mútua entre os fatores de EO e GCS, bem como a dependência de escolhas anteriores, são conferidas complexidade e relevância estratégica ainda maiores às decisões realizadas em ambas as áreas.

Palavras-chave: estratégia de operações, gestão da cadeia de suprimentos, indústria automobilística brasileira.

\section{Introdução}

Embora a implementação das práticas e filosofia da "produção enxuta" constitua um marco na indústria automobilística mundial, esta tem passado por transformações contundentes que, segundo Salerno et al. (2003), não se restringem ao lean manufacturing. De maneira sucinta, estas mudanças ocorrem em três grandes áreas: reestruturação interna da produção, pela adoção das práticas enxutas; configuração de novas relações de fornecimento, devido à formação dos blocos de comércio regionais e à introdução de novos arranjos organizacionais (modular, condomínio industrial, etc.); e mudanças nas atividades de projeto de produto, por meio das tecnologias $\mathrm{CAD} /$ $\mathrm{CAM} / \mathrm{CAE}$ e da introdução do conceito de carro mundial.
Segundo Humphrey e Salerno (2000), novos investimentos em mercados emergentes tornaram-se estratégicos não apenas para montadoras, mas também para os fornecedores de primeiro nível e subsidiárias de companhias transnacionais. Conseqüentemente, as indústrias automobilísticas destes países têm sido estruturalmente transformadas, tanto no que tange ao número e tamanho das empresas quanto ao padrão de relacionamento entre elas.

No Brasil, com a abertura da economia, a indústria automobilística passou por uma reestruturação importante a partir de 1995, quando diversas montadoras instalaram unidades produtivas em regiões sem tradição no setor automobilístico. Nesse período, as montadoras de automó- 
veis experimentaram um processo de crescimento e investimento, enquanto que as autopeças atravessavam um período de consolidação/desnacionalização (Posthuma, 1997).

No contexto da segunda frente de mudanças citada (novas relações de fornecimento), Alves Filho et al. (2002) ressaltam o impacto que os investimentos realizados pelas montadoras têm trazido nos arranjos das cadeias de suprimentos e na alteração do padrão de relacionamento montadora-fornecedor.

No período em questão, as montadoras de automóveis ganharam poder em relação aos fornecedores de autopeças. Com esse poder acumulado e comandando os investimentos feitos, as montadoras puderam definir, em grande parte, as configurações das cadeias industriais no setor. Segundo Alves Filho et al. (2000), as configurações das cadeias produtivas foram sendo definidas nas negociações das montadoras com seus fornecedores principais, especialmente nas ocasiões em que novas plantas estavam sendo instaladas.

Frente a esta transformação, puderam-se observar também impactos significativos nas unidades montadoras de motores das empresas montadoras de automóveis. Fenômenos como os motores de $1000 \mathrm{cc}$ e as joint-ventures para produção conjunta de motores permitem a constatação de que as montadoras de automóveis no Brasil adotaram, durante o período, estratégias competitivas distintas e estabeleceram novos tipos de relações com fornecedores de autopeças, em novas cadeias industriais (Maia e Cerra, 2004a), tendo, por conseguinte, que adotar Estratégias de Operações (EOs) e práticas de Gestão da Cadeia de Suprimentos (GCS) apropriadas a esses novos contextos.

Contudo, a teoria sobre Gestão da Cadeia de Suprimentos está embasada, segundo Alves Filho et al. (2004), em alguns pressupostos que contemplam, dentre outras questões, a necessidade de que as empresas da cadeia possuam suas estratégias devidamente alinhadas, de modo a enfrentar a competitividade e gerar ganhos para todos os seus elos. A Estratégia de Operações, por sua vez, abrange em suas áreas de decisão uma série de aspectos que são intimamente ligados à Gestão da Cadeia de Suprimentos. Questões como o nível de integração vertical, o planejamento e controle da produção, o desenvolvimento de produtos, entre outras, são fortemente influenciadas (ao mesmo tempo que influenciam) por aspectos estruturais, relacionais e estratégicos da GCS.

Desta forma, considerando a importância econômica do setor automotivo do Brasil, bem como a relevância das alterações que este setor tem sofrido, ao menos duas questões podem ser formuladas: 1) As estratégias de operações, por meio de suas prioridades competitivas e áreas de decisão, encontram-se consistentemente alinhadas entre as empresas pertencentes a cada cadeia de suprimentos do setor?; e 2) Até que ponto ocorre a influência mú- tua entre os aspectos estruturais e relacionais das cadeias e as prioridades e decisões da EO?

Diante destas questões, o presente trabalho tem por objetivo compreender os inter-relacionamentos entre a Estratégia de Operações e a Gestão da Cadeia de Suprimentos, analisando estudos de caso no setor automobilístico brasileiro, mais especificamente no segmento de produção de motores para automóveis. O motor foi aqui escolhido como componente a ser analisado pois: 1) representa porção significativa dos custos de produção dos veículos; 2) tem passado ultimamente por importantes inovações tecnológicas, por exemplo, motores de $1000 \mathrm{cc}$ mais potentes, operação com dois combustíveis, etc.; e 3) é composto por grande número de peças, fornecidas por várias empresas que compõem a cadeia de suprimentos.

Com base nos estudos de caso, podem-se identificar eventuais convergências e divergências entre as EOs e práticas de GCS adotadas pelas cadeias, bem como buscar ilustrar a dinâmica de interação existente entre ambas as áreas nas empresas estudadas.

$\mathrm{O}$ artigo encontra-se assim estruturado: inicialmente é realizada uma revisão bibliográfica acerca dos temas concernentes ao trabalho, ou seja, Estratégias de Operações e Gestão da Cadeia de Suprimentos. Posteriormente, descrevem-se o método e a pesquisa de campo realizada junto às montadoras de motores e seus fornecedores. Finalizando o trabalho, algumas conclusões são indicadas, assim como são apresentadas possibilidades para futuras pesquisas.

\section{Estratégia de operações}

Diferentes denominações vêm sendo utilizadas, em momentos diferentes, na literatura sobre Estratégia de Operações (EO): inicialmente, "estratégia de manufatura", evoluindo para "estratégia de produção" e, atualmente, para "estratégia de operações". Estas expressões diferentes não decorrem, entretanto, de mudanças nos conceitos e fundamentos teóricos, tendo as duas últimas sido propostas de modo a abarcar as aplicações também na gestão de serviços, além de na gestão da manufatura.

É atribuída a William Skinner a elaboração do conceito inicial sobre este assunto, por meio de seu artigo "Manufacturing - Missing Link in Corporate Strategy" (Skinner, 1969). Para o autor, a relação entre a estratégia da empresa e a manufatura não era facilmente compreendida, embora a política de produção necessitasse ser especificamente projetada para atender às necessidades definidas como estratégicas.

Diversas definições para o conceito de Estratégia de Operações podem ser encontradas na literatura, cada uma enfocando um aspecto particular da gestão de operações, ou uma escola de pensamento a respeito de estratégia. Será aqui adotada a definição de Hayes et al. (2004), para 
os quais "a estratégia de operações é um conjunto de objetivos, políticas e restrições auto-impostas que conjuntamente descrevem como a organização se propõe a dirigir e desenvolver todos os recursos investidos nas operações, de forma a melhor executar (e possivelmente redefinir) sua missão".

$\mathrm{Na}$ definição acima apresentada, podem ser identificadas duas orientações estratégicas distintas, porém complementares. Quando os autores comentam sobre objetivos e políticas, direcionamento de investimentos e execução da missão, estes se pautam na escola de planejamento estratégico - um processo formal e top-down que abrange o plano estratégico, tático e operacional (Oliveira, 2001). No entanto, quando tratam de restrições auto-impostas e redefinição de missão, estes se referem às competências estudadas pela visão baseada em recursos ( $R B V$ - Resource Based View). A $R B V$ advoga que as competências e recursos intangíveis das empresas são as origens da vantagem competitiva, sendo que tais recursos e competências desenvolvidos no presente e no passado condicionarão o direcionamento estratégico do futuro (Collis e Montgomery, 1995).

Sob a ótica do planejamento estratégico, a Estratégia de Operações é uma estratégia funcional e, portanto, deve promover sustentação à estratégia competitiva. Dado o fato de os elementos que compõem o sistema produtivo terem de ser concebidos para atingir determinados fins e realizar determinadas tarefas, estratégias competitivas diferentes poderão exigir configurações distintas do sistema de produção. Neste sentido, cada tipo de estratégia demanda certas tarefas da produção e especifica determinados objetivos, os quais são conhecidos por "prioridades competitivas" e foram inicialmente identificados por Skinner (1969) como sendo produtividade, serviço, qualidade e retorno sobre investimento.

Em trabalhos subseqüentes, outros autores apresentaram diferentes combinações de prioridades como, por exemplo, custo, qualidade, confiabilidade e flexibilidade (Hayes e Wheelwright, 1984; Ward e Duray, 2000; Kathuria, 2000; Demeter, 2003). A este conjunto, Hill (2000); Slack, Chambers e Johnston (2002) adicionaram uma dimensão relativa à velocidade, e Dangayach e Deshmukh (2003) contemplaram ainda o aspecto inovação. Embora o aspecto velocidade seja aqui considerado, a inovação será tratada como agente facilitador das outras prioridades competitivas, possibilitando, por exemplo, ampliar a flexibilidade de introdução de novos produtos, reduzir custos por meio do reprojeto de processos, etc.

Diante destas considerações, o modelo de prioridades aqui adotado é o de Garvin (1993), que apresenta as prioridades como sendo custo, qualidade, entrega, flexibilidade e serviço. Este modelo, com ampla aceitação na literatura, ainda desdobra as prioridades competitivas em várias subprioridades, conforme mostra a Tabela 1.
As prioridades competitivas variam conforme as diferentes circunstâncias competitivas e a estratégia da empresa. Além disso, não há um consenso sobre quais devam ser os conjuntos delas que orientam a implementação da estratégia de operações.

Segundo Nogueira (2002), um aspecto importante a ser considerado quando se projeta ou opera um sistema de produção é a necessidade da realização de trade-offs. Variáveis como custo, qualidade, flexibilidade, entrega e serviço ao cliente colocam a administração constantemente diante de situações de decisão em que escolhas (por uma ou por algumas poucas prioridades) são inevitáveis.

A realização de trade-offs está associada às áreas de decisão estrutural e infra-estrutural. De acordo com Skinner (1969), o fundamental na tomada de decisão é garantir que a alternativa selecionada seja apropriada às tarefas da manufatura determinada pela estratégia competitiva da empresa.

A proposição da necessidade de realização de trade-offs tem sido responsável por umas das principais controvérsias existentes na literatura relativa ao conceito de estratégia de operações. Como exemplo desta discordância, diversos autores desenvolvem e advogam suas idéias em pelo menos três diferentes correntes de pensamento: a visão tradicional, a cumulativa e a integrativa (Boyer e Lewis, 2002).

A visão tradicional de trade-offs segue a linha de pensamento de Skinner (1969), para quem as escolhas entre enfatizar uma ou outra prioridade competitiva serão inevitáveis, nas mais diversas circunstâncias.

Na visão cumulativa, Ferdows e De Meyer (1990) criticam a visão tradicional a respeito de incompatibilidades entre as prioridades competitivas. Esses autores, a partir de uma pesquisa que desenvolveram na década de oitenta em empresas européias, japonesas e norte-americanas, verificaram que várias empresas estavam obtendo bons desempenhos em algumas das prioridades competitivas ao mesmo tempo. Baseados nesta pesquisa, eles puderam propor o "modelo do cone de areia", em que as capacidades poderiam ser acumuladas e "construídas" umas sobre as outras.

Buscando uma combinação das duas visões anteriores, a visão integrativa prega que os elementos de ambos os pontos de vista são aplicáveis. O "modelo pivô" de Da Silveira e Slack (2001), apresentado na Figura 1, é um exemplo de abordagem integrativa. Para estes autores, existem certas escolhas a serem realizadas entre as prioridades (como os dois extremos de uma gangorra), mas o acúmulo de competências faz com que todas as prioridades competitivas tenham seus níveis absolutos aumentados (elevando a altura do pivô da gangorra).

Também adotando a visão integrativa, Hayes et al. (2004) comentam a existência de trade-offs de primeiro (impacto no presente) e segundo (impacto no 
Tabela 1. Subprioridades competitivas da produção. Fonte: Garvin (1993).

\begin{tabular}{|c|c|}
\hline Prioridades & Subprioridades \\
\hline Custo & $\begin{array}{l}\text { - Custo inicial - o preço ou o custo para se adquirir um produto; } \\
\text { - Custo operacional - o custo para operar ou usar um produto ao longo de sua vida útil; e } \\
\text { - Custo de manutenção - o custo para manutenção de um produto ao longo de sua vida útil. Inclui pequenos reparos e } \\
\text { reposição de peças. }\end{array}$ \\
\hline Qualidade & $\begin{array}{l}\text { - Desempenho - as características primárias para operação de um produto ou serviço; } \\
\text { - Características - as características secundárias de um produto ou serviço; } \\
\text { - Confiabilidade - a probabilidade de um produto ou serviço falhar durante certo período de tempo; } \\
\text { - Conformidade - o grau em que um produto ou serviço reúne os padrões preestabelecidos; } \\
\text { - Durabilidade - o número de vezes que um produto pode ser usado antes de deteriorar-se fisicamente ou não ser viável } \\
\text { economicamente repará-lo; } \\
\text { - Nível de serviço - depende da velocidade, da cortesia e da competência dos reparos; } \\
\text { - Estética - a aparência, o sentimento, o gosto, o cheiro e o som de um produto ou serviço; e } \\
\text { - Qualidade percebida - o impacto da marca, a imagem da empresa e a propaganda. }\end{array}$ \\
\hline Entr & $\begin{array}{l}\text { - Precisão - se os itens corretos foram entregues nas quantidades certas; } \\
\text { - Completude - se os carregamentos (entregas) foram completos na primeira vez ou se houve necessidade de emitirno- } \\
\text { vos pedidos para determinados itens; } \\
\text { - Confiabilidade - se os produtos foram entregues na data estipulada; } \\
\text { - Disponibilidade - a probabilidade de ter em estoque certo item no momento da emissão do pedido; } \\
\text { - Velocidade - o tempo decorrido entre a emissão do pedido e a entrega do produto ao consumidor; } \\
\text { real; } \\
\text { - Facilidade de emissão de pedidos - a maneira como a empresa recebe os pedidos (eletronicamente ou não) e informa } \\
\text { os itens que estão em estoque; } \\
\text { - Qualidade - a condição do produto após o transporte; } \\
\text { - Flexibilidade de emissão de pedidos - se há limites estabelecendo o número mínimo de itens por pedido e selecio- } \\
\text { nando os itens de um pedido isolado; } \\
\text { - Flexibilidade de transporte - a habilidade de modificar o roteiro de entrega para atender a circunstâncias espe- } \\
\text { ciais; e } \\
\text { - Facilidade de retorno - a disposição de absorver os custos de retorno de um produto e a velocidade com que os re- } \\
\text { tornos são processados. }\end{array}$ \\
\hline & $\begin{array}{l}\text { - Flexibilidade de produto } \\
\text { - Novos produtos - a velocidade com que os produtos são criados, projetados, manufaturados e introduzidos; } \\
\text { - Customização - habilidade de projetar um produto para atender às especificações de um cliente particular; e } \\
\text { - Modificação - a habilidade de modificar os produtos existentes para atender a necessidades especiais; } \\
\text { - Flexibilidade de volume } \\
\text { - Previsões incertas - a habilidade de responder a súbitas mudanças no volume de um produto requerido pelo mer- } \\
\text { cado; e } \\
\text { - Aumento de escala de novos processos - a velocidade com que novos processos de manufatura podem variar a } \\
\text { produção de pequenos volumes em grandes escalas; } \\
\text { - Flexibilidade de processo } \\
\text { - Flexibilidade de mix - a habilidade de produzir uma variedade de produtos, em um curto espaço de tempo, sem } \\
\text { modificar as instalações existentes; } \\
\text { - Flexibilidade de substituição - a habilidade de ajustar as mudanças no mix de produtos a longo prazo; } \\
\text { - Flexibilidade de roteiro - o grau em que a seqüência de fabricação ou de montagem pode ser modificada se uma } \\
\text { máquina ou um equipamento estiver com problemas; } \\
\text { - Flexibilidade de materiais - a habilidade de acomodar variações e substituições das matérias-primas; e } \\
\text { - Flexibilidade nos seqüenciamentos - a habilidade de modificar a ordem de alimentação dos pedidos no processo } \\
\text { produtivo, em razão de incertezas no fornecimento de componentes e materiais. }\end{array}$ \\
\hline Serviço & $\begin{array}{l}\text { - Apoio ao cliente - a habilidade de atender o cliente rapidamente pela substituição de peças defeituosas ou de reabas- } \\
\text { tecimento de estoques para evitar paradas para manutenção ou perdas de vendas; } \\
\text { - Apoio às vendas - a habilidade de melhorar as vendas por meio de informações em tempo real sobre a tecnologia, o } \\
\text { equipamento, o produto ou o sistema que a empresa está vendendo; } \\
\text { - Resolução de problemas - a habilidade em assistir grupos internos e clientes na solução de problemas, especialmente } \\
\text { em áreas como desenvolvimento de novos produtos, projetos, considerando a manufaturabilidade e a melhoria da } \\
\text { qualidade; e } \\
\text { - Informação - a habilidade de fornecimento de dados críticos a respeito de desempenho de produto, parâmetros de } \\
\text { processo e custos para grupos internos, tais como P\&D, e para clientes que então utilizam os dados para melhorar } \\
\text { suas próprias operações ou produtos. }\end{array}$ \\
\hline
\end{tabular}


futuro) graus. Desta forma, as escolhas estratégicas realizadas no presente não somente direcionarão as operações hoje, mas condicionarão as possibilidades de estratégias no futuro, em um fenômeno conhecido como "dependência de trajetória" (do inglês, path dependence).

Assim, pode-se considerar que os trade-offs continuam sendo um elemento importante na teoria a respeito da estratégia de operações, embora tenham ocorrido, nos últimos trinta anos, significativas mudanças tecnológicas, surgido novas demandas da sociedade, mudado os perfis dos consumidores e ocorrido ainda outras mudanças no ambiente que afetaram o projeto e a operação dos sistemas produtivos e, assim, a natureza e os tipos de objetivos da produção.

As prioridades competitivas refletem necessidades da estratégia competitiva e apontam para determinados objetivos a serem atingidos pelo sistema produtivo. Para esses objetivos serem alcançados, é necessário o desenvolvimento de um padrão de ações relacionadas a um conjunto de áreas de decisões. Em seu trabalho inicial, Skinner (1969) exemplificou escolhas possíveis em cinco

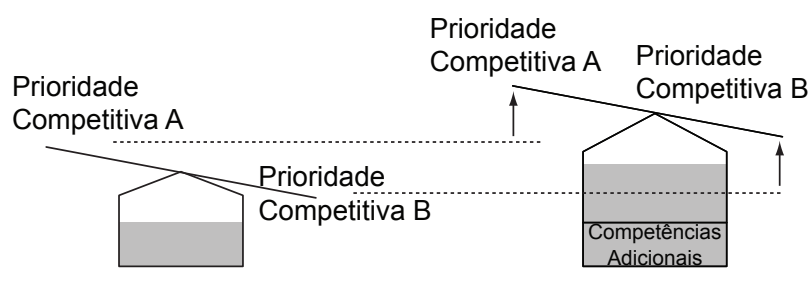

Figura 1. Modelo de pivô dos trade-offs. Fonte: (adaptado de Da Silveira e Slack, 2001). áreas de decisão: planta e equipamento, planejamento e controle da produção, mão-de-obra e estrutura administrativa, projeto do produto/engenharia, e organização e administração.

A partir da proposição de Skinner, Hayes et al. (1988) propuseram uma nova classificação (representada na Tabela 2), com dez áreas de decisão, agrupadas sob duas categorias: estruturais e infra-estruturais. As decisões estruturais possuem impactos a longo prazo, sendo difíceis de serem revertidas ou modificadas e exigem vultosos investimentos de capital. As decisões de natureza infra-estruturais estão relacionadas a aspectos mais operacionais do negócio, possuindo resultados tanto a curto, como a médio e a longo prazo.

O corpo teórico de estratégia de operações até aqui apresentado é fortemente pautado pela teoria de planejamento estratégico. No entanto, segundo Schroeder et al. (2002), a visão baseada em recursos pode abordar várias das deficiências desta abordagem tradicional de estratégia de operações.

Sob a ótica da $R B V$, a estratégia de operações compreende "decisões sobre, e o gerenciamento estratégico de: competências, capacidades e processos; tecnologia; recursos; e atividades táticas chave necessárias em qualquer rede de suprimentos, de forma a criar e entregar produtos ou serviços exigidos pelo consumidor. O papel estratégico envolve combinar estes 'blocos básicos' em uma ou mais arquiteturas estratégias únicas e específicas à organização" (Lowson, 2003: 538).

Neste contexto, três grandes frentes de pesquisa dentro da literatura de operações têm se amparado na $R B V$ para buscar desenvolvimento de novas teorias (Gagnon, 1999):

Tabela 2. Áreas de decisão em estratégia de produção. Fonte: adaptada de Hayes et al. (1988).

\begin{tabular}{|c|c|}
\hline Áreas de decisão & Decisões a serem tomadas \\
\hline \multicolumn{2}{|l|}{ Decisões Estruturais } \\
\hline Capacidade & A capacidade de produção total a ser provida. \\
\hline Instalações & $\begin{array}{l}\text { O número de plantas, a localização e a especialização de cada planta necessária para se atingir o volu- } \\
\text { me de produção desejado. }\end{array}$ \\
\hline Tecnologia & $\begin{array}{l}\text { Os tipos de equipamentos e sistemas a serem utilizados em cada unidade, o grau de automação do } \\
\text { processo e a forma de ligação entre as plantas. }\end{array}$ \\
\hline Integração vertical & $\begin{array}{l}\text { Os materiais, sistemas e os serviços a serem providos internamente e aqueles que devem ser fornecidos } \\
\text { por terceiros (e também o tipo de relacionamento a ser desenvolvido com os fornecedores). }\end{array}$ \\
\hline \multicolumn{2}{|l|}{ Decisões Infra-estruturais } \\
\hline Recursos humanos & As políticas e as práticas de recursos humanos, incluindo administração, seleção e treinamento. \\
\hline Qualidade & Os sistemas de controle e garantia da qualidade (prevenção de defeitos, monitoramento, intervenção). \\
\hline $\begin{array}{l}\text { Planejamento e controle da } \\
\text { produção/materiais }\end{array}$ & $\begin{array}{l}\text { Sistemas de planejamento da produção e controle de estoque, políticas de fornecimento, regras de } \\
\text { decisão. }\end{array}$ \\
\hline Novos produtos & O processo de desenvolvimento de novos produtos. \\
\hline Medidas de desempenho & Indicadores de desempenho e sistemas de recompensa incluindo sistema de alocação de capital. \\
\hline Organização & A estrutura organizacional, sistemas de controle e remuneração, papel dos grupos de staff. \\
\hline
\end{tabular}


- O papel ativo da produção na estratégia - a abordagem baseada em recursos tem sido vista como uma forma de conferir aspecto pró-ativo à produção, em lugar de meramente suportar a estratégia competitiva definida pela empresa. Para Hayes e Pisano (1996), as companhias que obtêm sucesso a longo prazo o fazem sendo capazes de desempenhar certas coisas melhor que seus competidores. Desta forma, como a maioria das competências críticas de uma companhia reside na produção, tem-se um aumento de sua importância no desenvolvimento da estratégia competitiva;

- A questão dos trade-offs - a maior parte das pesquisas se concentra no caráter dinâmico das prioridades competitivas, tanto buscando explicar como capacidades e competências parecem alterar as relações de trade-off quanto tentando retratar o reflexo que as escolhas dos trade-offs terão no futuro da estratégia de operações da empresa; e

- A implementação das práticas de classe mundial - Hayes e Pisano (1994) destacam que a estratégia de operações não deve ceder lugar à simples implementação destas práticas, como se estas constituíssem panacéia para todos os problemas das empresas. Ao contrário, os autores defendem que tais programas e práticas devem ser implementados como passos consecutivos no caminho de uma direção estratégica desejada. Desta forma, a estratégia de operações deve buscar construir competências que serão necessárias para a empresa no futuro. Programas como TQM (Total Quality Management), JIT (Just In Time) e outros não devem ser vistos como fins, mas como programas de melhoria da produção que desenvolverão habilidades e capacidades para a empresa distinguir-se competitivamente a longo prazo.

É também importante considerar que a função operações e, conseqüentemente, a estratégia que pauta suas decisões provêem significativa contribuição aos diversos processos de negócios que existem dentro das empresas. Embora esta perspectiva de processos seja relevante também em EO, preferiu-se apresentar este aspecto na próxima seção (sobre GCS), considerando-se as limitações de espaço para este artigo e a importância ainda maior destes processos no funcionamento das cadeias de suprimentos.

\section{Gestão da Cadeia de Suprimentos (Supply Chain Management)}

Os esforços para o desenvolvimento de abordagens para o estudo de cadeias de suprimentos são relativamente recentes. Apenas no início da década de 90, lastreado pelo amplo desenvolvimento da logística, o assunto começa a ser sistematicamente tratado em periódicos científicos nas áreas de Administração e Engenharia de Produção no ocidente, com a difusão do novo padrão de relacionamento entre montadoras e fornecedores da indústria automobilística japonesa (Alves Filho et al., 2004).

Antes de buscar uma definição para a Gestão da Cadeia de Suprimentos (GCS), é necessário compreender qual o objeto que será gerido por estas práticas. Segundo Chopra e Meindl (2003), uma cadeia de suprimentos engloba todos os estágios (clientes, varejistas, distribuidores, fabricantes e fornecedores) envolvidos, direta ou indiretamente, no atendimento de um pedido ao cliente. Pode ser vista, de acordo com Lumus et al. (1998), como uma rede de entidades que abrange todo o fluxo de materiais e informações.

Esta cadeia de empresas, enxergada como um conjunto, traz uma série de desafios para as práticas gerenciais tradicionais. $\mathrm{O}$ forte controle hierárquico, anteriormente exercido pela Integração Vertical, não é mais factível na situação em que empresas distintas detêm a operação de diferentes etapas do processo produtivo, acumulando competências inerentes a tais etapas e necessitando traçar estratégias para servir seus vários clientes.

Neste novo contexto de relações, surge a Gestão da Cadeia de Suprimentos. Segundo Pedroso (2002:21), a GCS pode ser definida como "a integração dos principais processos que gerenciam os fluxos bidirecionais de materiais e informações no âmbito intra-empresa e entre empresas participantes da cadeia de suprimentos, até atingir os consumidores finais, cujo objetivo principal é agregar valor aos acionistas e aos clientes ao longo destes processos". Este conceito atual tem trazido interessantes contribuições para as indústrias, sobretudo a automobilística (Pires, 1998).

Segundo Cooper et al. (1997) e Tan (2002), a GCS envolve a integração dos processos de negócios por meio da cadeia de suprimentos, abrangendo a coordenação de atividades e processos não apenas dentro de uma organização isolada, mas entre todas as que compõem a cadeia de suprimentos. A GCS baseia-se na idéia de que empresas devem estar estratégica e holisticamente integradas com os seus fornecedores e clientes (Pires, 2001).

Embora cada empresa da cadeia tenha seus clientes diretos, a cadeia como um todo, cumulativamente, agrega valor ao produto/serviço que será entregue ao cliente final. Desta forma, o objetivo da Gestão da Cadeia de Suprimentos é maximizar a sinergia entre todas as partes da cadeia, a fim de atender o cliente final da maneira mais eficiente possível. Para Alves Filho et al. (2001), o objetivo é tornar os processos de negócio mais eficientes e eficazes, reduzindo custos, níveis de estoque, melhorando a qualidade e criando vantagem competitiva e valor para a cadeia de suprimentos.

O foco na satisfação do cliente final impõe desafios de integração, visibilidade e coordenação entre todas as empresas. Flutuações na demanda final, associadas a um fluxo deficiente de informações entre as empresas, pos- 
suem seus impactos amplificados conforme se caminha a montante na cadeia (fato conhecido como efeito "chicote") (Slack et al., 2002). Embora o efeito "chicote" seja relevante e um bom exemplo didático, uma série de outros problemas pode ser originada pelas dificuldades de integração e relacionamento entre empresas.

Desta forma, um dos princípios norteadores da GCS é "assegurar maior visibilidade dos eventos relacionados à satisfação da demanda, com o objetivo de minimizar os custos das operações produtivas e logísticas entre empresas, constituintes do fluxo de materiais, componentes e produtos acabados" (Christopher, 1998; Handfield e Nichols, 1999; Chopra e Meindel, 2003 apud Assumpção, 2003:346).

Alves Filho et al. (2004) sintetiza os principais pressupostos da GCS, agrupados em quatro subconjuntos relacionados, respectivamente, 1) ao ambiente competitivo; 2) ao alinhamento estratégico das organizações e à repartição dos ganhos; 3 ) à estrutura da cadeia; e 4) às relações entre as empresas da cadeia.

$\mathrm{O}$ primeiro subconjunto de pressupostos se refere à maneira pela qual as companhias e os pesquisadores percebem o ambiente competitivo. Segundo (Christopher, 1998), tal ambiente passou por um processo de reestruturação, de forma que a competição agora ocorre entre cadeias inteiras, e não mais entre empresas isoladas.

O segundo grupo de pressupostos deriva do primeiro. Se agora a competição ocorre entre cadeias inteiras, as companhias devem ter suas estratégias alinhadas, de forma que ações individuais gerem ganhos para toda a cadeia. A contrapartida do alinhamento estratégico seria uma distribuição de ganhos equânime entre as empresas, de acordo com os esforços e investimentos feitos por cada uma.

O primeiro e o segundo conjunto de pressupostos possuem relação imediata com os objetivos deste trabalho. A alteração no padrão de competição e a necessidade de alinhamento estratégico possuem impacto direto nas estratégias competitivas e, conseqüentemente, na estratégia de operações implementada por cada companhia da cadeia.

O terceiro subconjunto contempla aspectos relativos à estrutura, isto é, o papel que cada companhia e cada unidade produtiva deve desempenhar dentro das cadeias. Ele inclui a existência de um número agora relativamente pequeno de fornecedores hierarquizados, a integração de processos e atividades por meio da cadeia, a ocorrência de um fluxo bidirecional eficiente de materiais e informação e a realização de esforços por parte de cada empresa para reduzir sua própria complexidade (reduzindo assim a complexidade da cadeia como um todo).

O quarto grupo se refere às relações entre as companhias que fazem parte da cadeia de suprimentos. Ele lida com o estabelecimento de relações cooperativas e de longo prazo, assim como parcerias entre as empresas.
Para Ballou (1999), o aumento do interesse pelas relações de parceria deve-se ao fato de não existir mais a possibilidade de uma única empresa ter todo o controle do fluxo dos produtos ou serviços, da fonte da matéria-prima ao consumo final. As relações de parceria buscam integrar empresas distintas, responsáveis por diferentes etapas do processo produtivo, em um modelo de integração alternativo à hierarquia da Integração Vertical.

Buscando uma definição para o conceito de parceria, Lamming apud Slack et al. (2002:433) apresenta parceria como um padrão de relacionamento pautado "no compartilhamento de riscos e recompensas de tecnologia e inovação, levando à redução de custos, ao aprimoramento na entrega e na qualidade e à ampliação de vantagem competitiva".

Os relacionamentos de parceria, segundo Mchug et al. (2003), guardam alguns aspectos comuns como, por exemplo: relacionamento de longo prazo baseado em confiança mútua e em cooperação mais do que em competição; forte interesse do fornecedor pela qualidade dos produtos que são entregues; e cooperação visando o aumento de desempenho dos fornecedores.

A confiança mútua, um dos requisitos para o estabelecimento de parcerias, é fortemente condicionada por outro pressuposto da Gestão da Cadeia de Suprimentos: as relações de longo prazo. Relações de longo prazo podem implicar ligações de confiança entre as empresas, na medida em que as transações ocorrem reiteradamente entre os diversos elos da cadeia (Maia e Cerra, 2004a).

Considerando o que foi exposto nessa seção, pode-se concluir que a Gestão da Cadeia de Suprimentos é um conceito com caráter fortemente estratégico e, conseqüentemente, as empresas necessitam acompanhar o desempenho de seus processos de GCS. Contudo, a medição de desempenho na cadeia é ainda um campo em desenvolvimento, no qual diversos autores realizam proposições enfocando aspectos específicos. Como exemplos, têm-se: enfoque em custos (Damme e Zon, 1999), eficiência na utilização de recursos, saídas/serviços aos clientes e flexibilidade às mudanças do ambiente (Beamon, 1999), níveis de estoque, tempo, atendimento aos pedidos, qualidade, foco no cliente, satisfação dos clientes (Ramdas e Sperkman, 2000).

As duas seções anteriores buscaram realizar uma síntese teórica a respeito dos temas envolvidos nesse trabalho, ou seja, Estratégia de Operações e Gestão da Cadeia de Suprimentos. Seus elementos constituintes - as prioridades competitivas e as áreas de decisão da EO, e as questões estruturais, relacionais e de alinhamento da GCS - possuem relações (entre si) que ainda precisam ser identificadas e discutidas para o desenvolvimento de uma gestão estratégica das operações em cadeias de suprimentos. Algumas destas relações serão empiricamente analisadas na pesquisa descrita em seguida. 


\section{Método de pesquisa}

A estratégia de pesquisa adotada foi o estudo de caso, dado em que se ambicionava verificar, empiricamente, convergências e divergências entre EOs e práticas de GCS, bem como ilustrar a dinâmica de interação existente entre ambas as áreas em empresas do segmento de motores para automóveis. A escolha desta abordagem está em concordância com as proposições de Yin (1994:23), pois se desejava "investigar um fenômeno atual dentro do seu contexto real, quando as fronteiras entre o fenômeno e o contexto não são claramente definidas e utilizando-se várias fontes de evidência".

A pesquisa de campo, tendo sido realizada por meio de estudos de caso, utilizou-se de um método qualitativo, de pesquisa descritiva (ou exploratória). Segundo Lazzarini (1997), os métodos denominados qualitativos caracterizam-se por um foco maior na compreensão dos fatos que propriamente na sua mensuração. Eles são empregados, de acordo com Richardson (1985), em casos em que a riqueza dos detalhes é mais relevante do que as informações quantitativas.

A técnica de obtenção de dados empreendida foi a entrevista, que, segundo Selltiz et al. (1967:273) apud Gil (1999), "é bastante adequada para a obtenção de informações acerca do que as pessoas sabem, crêem, esperam, sentem ou desejam, pretendem fazer, fazem ou fizeram, bem como acerca das suas explicações ou razões a respeito das coisas precedentes". Com este intuito, foram conduzidas entrevistas semi-estruturadas, de cerca de uma hora cada, em duas montadoras de motores para automóveis e em dois de seus fornecedores, seguindo-se um roteiro previamente formulado a partir da revisão da literatura.

Nas empresas, as pessoas entrevistadas foram aquelas ligadas à gestão da produção, qualidade, produtos e de processos, além de diretores industriais e gerentes de compras.

Para analisar as Estratégias de Operações (EOs) foram consideradas as informações obtidas a respeito das prioridades competitivas e das características das áreas estruturais e infra-estruturais dessas empresas. A análise da Gestão da Cadeia de Suprimentos (GCS), por sua vez, se baseou em informações acerca da estrutura das cadeias e das relações entre as empresas que as compõem.

A partir da análise das EOs das montadoras e de seus fornecedores, pôde ser investigado o alinhamento estratégico da cadeia, comparando aspectos competitivos enfatizados pelas empresas e compatibilidade de suas decisões estruturais e infra-estruturais. Em um passo seguinte, o exame dos aspectos estruturais e relacionais das cadeias permitiu identificar se estes influenciam (e são influenciados por) as questões do âmbito da Estratégia de Operações.

\section{Estudos de caso}

\subsection{Apresentação das empresas}

Os estudos de caso foram realizados em duas montadoras de motores para automóveis e em dois de seus fornecedores. De forma a não identificá-las, elas serão aqui chamadas de montadoras " $\mathrm{A}$ " e "B" e fornecedores "C" e "D".

A montadora "A" produz motores para automóveis (motores 1.0 a 1.6), envolvendo uma grande diversidade de produtos. Trabalha em 3 turnos de produção, sendo que o terceiro turno produz metade da produção dos demais. Cada turno tem a capacidade de produzir 600 motores, mas produz 550 devido ao mix de produção. Desta forma, a planta possui capacidade de produção aproximada de 38 mil motores por mês, sendo que exporta por volta de 3000 motores/mês.

A montadora "B" lida com motores de baixa e média cilindradas (motores 1.0 a 1.8 ). Na subsidiária brasileira, a fabricação de motores divide-se em três áreas: a) usinagem do bloco motor, virabrequim e cabeçote; b) montagem final; e c) manutenção e trocas de ferramentas. Existe um Sistema Integrado da Qualidade, pelo qual monitora-se a montagem de um motor desde a usinagem da primeira peça até o encarroçamento do motopropulsor no veículo. Possui capacidade instalada para a produção de aproximadamente 55 mil motores por mês, em três turnos, e 50 mil transmissões/mês, também em três turnos.

O fornecedor " $\mathrm{C}$ " produz embreagens para veículos de passeio, veículos pesados e agrícolas. As duas plantas instaladas no Brasil, trabalhando em três turnos, possuem capacidade para produzir 14.000 embreagens por mês, englobando tanto a produção para a montadora quanto para o mercado de reposição.

O fornecedor " $D$ " produz peças fundidas, como carcaças de transmissão, carters de óleo e agregados para motores (suporte para compressor do ar condicionado, tampa de cabeçote, etc.). O processo produtivo é basicamente composto por três etapas: fundição, usinagem e montagem. Tem capacidade para produção de até 1300 toneladas em peças/mês, trabalhando em três turnos.

Para a compreensão da organização das cadeias, é necessário ressaltar que o fornecedor " $\mathrm{C}$ " produz componentes para a montadora "A", mas somente atua em peças de reposição para "B". O fornecedor " $D$ " fornece para a montadora "B", mas não para "A".

\subsection{Estratégia de operações}

De forma a caracterizar o conteúdo das Estratégias de Operações empreendidas pelas companhias analisadas, foram levantadas as principais variáveis referentes às prioridades competitivas e às áreas de decisão estruturais e infra-estruturais. Alguns destes aspectos (principal- 
mente os estruturais) constam das apresentações acima realizadas, enquanto que os outros são sintetizados na Tabela 3 .

\subsection{Gestão da Cadeia de Suprimentos}

Com o intuito de caracterizar a Gestão das Cadeias de Suprimento analisadas, foram levantadas as principais

Tabela 3. Características relevantes da Estratégia de Produção nas montadoras e fornecedores.

\begin{tabular}{|c|c|c|c|c|}
\hline & Montadora de Motores & $\begin{array}{c}\text { Montadora de Motores } \\
\text { "B" }\end{array}$ & Fornecedor "C" & Fornecedor "D" \\
\hline $\begin{array}{l}\text { Prioridades } \\
\text { competitivas }\end{array}$ & $\begin{array}{l}\text { Flexibilidade, Custo e } \\
\text { Entrega. }\end{array}$ & $\begin{array}{l}\text { Flexibilidade, Custo e } \\
\text { Qualidade. }\end{array}$ & $\begin{array}{l}\text { Flexibilidade, Custo, Qua- } \\
\text { lidade e Entrega. }\end{array}$ & Entrega e Custo. \\
\hline \multirow[t]{2}{*}{$\begin{array}{l}\text { Gestão da } \\
\text { qualidade }\end{array}$} & $\begin{array}{l}\text { Certificada em ISO } 9002 \text {, } \\
\text { QS } 9000 \text {, ISO } 14001, \\
\text { além de normas do país de } \\
\text { origem da empresa. Está } \\
\text { em vias de se certificar em } \\
\text { TS } 16949 \text {. }\end{array}$ & $\begin{array}{l}\text { Certificada em ISO 9002, } \\
\text { QS } 9000 \text {, ISO TS } 16949 \text {, e } \\
\text { ISO } 14001 .\end{array}$ & $\begin{array}{l}\text { Certificados em ISO 9001, } \\
\text { ISO TS } 16949 \text { e ISO } \\
14001 .\end{array}$ & $\begin{array}{l}\text { São certificados em } \\
\text { ISO } 9001 \text { e ISO TS } 16949 .\end{array}$ \\
\hline & $\begin{array}{l}\text { FMEA, PFMEA, CEP, } \\
\text { pontos de verificação den- } \\
\text { tro do processo e programa } \\
\text { de sugestões. }\end{array}$ & $\begin{array}{l}\text { Utilizam MASP, Engenha- } \\
\text { ria Estatística, TPM, CEP, } \\
\text { Auditoria de Processo, } \\
\text { FMEA, e Programa de } \\
\text { Sugestões. }\end{array}$ & $\begin{array}{l}\text { Possui inspeção ao longo } \\
\text { do processo, e utiliza técni- } \\
\text { cas como MASP, poka- } \\
\text { yoke e kaizen. Iniciam } \\
\text { projeto para implementar } \\
\text { 6-sigma. }\end{array}$ & $\begin{array}{l}\text { Utilizam ferramentas como } \\
\text { FMEA, CEP, PDCA } \\
\text { 8D e reuniões para resolu- } \\
\text { ção de problemas. } \\
\text { Iniciam projeto para imple- } \\
\text { mentar 6-sigma. }\end{array}$ \\
\hline \multirow[t]{3}{*}{$\begin{array}{l}\text { Gestão da } \\
\text { tecnologia e } \\
\text { desenvolvimento } \\
\text { de produtos }\end{array}$} & $\begin{array}{l}\text { Possui autonomia frente } \\
\text { à matriz no exterior para } \\
\text { desen-volvimentos incre- } \\
\text { mentais nos motores. }\end{array}$ & $\begin{array}{l}\text { Possui autonomia frente } \\
\text { à matriz no exterior para } \\
\text { desenvolvimentos incre- } \\
\text { mentais nos motores. }\end{array}$ & $\begin{array}{l}\text { Detém a tecnologia de } \\
\text { produto e de processo de } \\
\text { produção de embreagens. }\end{array}$ & $\begin{array}{l}\text { O projeto inicial do produ- } \\
\text { to é fornecido pelas monta- } \\
\text { doras. A empresa contribui } \\
\text { no sentido de adequá-lo à } \\
\text { produção. }\end{array}$ \\
\hline & $\begin{array}{l}\text { Os motores bi-combustível } \\
\text { e para exportação são os } \\
\text { mais recentes desenvolvi- } \\
\text { mentos. }\end{array}$ & $\begin{array}{l}\text { Os motores bi-combustível } \\
\text { são o mais recente desen- } \\
\text { volvimento. }\end{array}$ & $\begin{array}{l}\text { Inovações incrementais em } \\
\text { produtos surgem de especi- } \\
\text { ficações de clientes. }\end{array}$ & $\begin{array}{l}\text { Possuem grande autono- } \\
\text { mia de desenvolvimento } \\
\text { frente à matriz interna- } \\
\text { cional. }\end{array}$ \\
\hline & $\begin{array}{l}180 \text { pessoas em DP de } \\
\text { motores. }\end{array}$ & $\begin{array}{l}163 \text { pessoas } \\
\text { em DP de motores. }\end{array}$ & & \\
\hline $\begin{array}{l}\text { Organização } \\
\text { do trabalho }\end{array}$ & $\begin{array}{l}\text { Existem } 7 \text { grupos de traba- } \\
\text { lho, tendo cada um de } 8 \text { a } \\
12 \text { pessoas (um monitor e } \\
\text { um líder). } \\
\text { Ocorre rodízio, por fatores } \\
\text { ergonômicos e psíquicos. }\end{array}$ & $\begin{array}{l}\text { Existem } 7 \text { células, cada } \\
\text { uma com } 12 \text { operários. } \\
\text { Cada uma possui líder } \\
\text { definido. }\end{array}$ & $\begin{array}{l}\text { Existem } 11 \text { células, e a } \\
\text { empresa possui condições } \\
\text { de montar novas, caso } \\
\text { necessário. }\end{array}$ & $\begin{array}{l}\text { Células com } 1 \text { ou } 2 \text { opera- } \\
\text { dores. Não existe rodízio } \\
\text { programado, mas isto } \\
\text { ocorre devido ao mix de } \\
\text { produção. }\end{array}$ \\
\hline \multirow[t]{2}{*}{$\begin{array}{l}\text { Recursos } \\
\text { humanos }\end{array}$} & $\begin{array}{l}\text { Aproximadamente } \\
450 \text { funcionários. }\end{array}$ & $\begin{array}{l}\text { Aproximadamente } 230 \\
\text { mensalistas e } 1500 \text { horis- } \\
\text { tas. }\end{array}$ & $\begin{array}{l}\text { Aproximadamente } \\
300 \text { funcionários, mais } \\
50 \text { terceiros. }\end{array}$ & $\begin{array}{l}\text { Aproximadamente } \\
420 \text { funcionários. }\end{array}$ \\
\hline & $\begin{array}{l}\text { Identificaram necessidade } \\
\text { de treinamento comporta- } \\
\text { mental. }\end{array}$ & $\begin{array}{l}\text { O número tem se reduzido } \\
\text { nos últimos } 10 \text { anos. }\end{array}$ & $\begin{array}{l}\text { Pretende ampliar o treina- } \\
\text { mento interno. }\end{array}$ & $\begin{array}{l}\text { Tem ocorrido incentivo a } \\
\text { cursos de formação. }\end{array}$ \\
\hline \multirow[t]{2}{*}{$\begin{array}{l}\text { Planejamento } \\
\text { e controle da } \\
\text { produção }\end{array}$} & $\begin{array}{l}\text { Recebe pedidos mensais, } \\
\text { revistos diariamente. Re- } \\
\text { cebe também estimativas } \\
\text { para próximos } 3 \text { meses. }\end{array}$ & $\begin{array}{l}\text { Recebe pedidos semanais } \\
\text { (fixo para a semana e pre- } \\
\text { visão para } 6 \text { meses) }\end{array}$ & $\begin{array}{l}\text { Fornecedor recebe infor- } \\
\text { mações semanais, com } \\
\text { previsão para } 6 \text { meses. }\end{array}$ & $\begin{array}{l}\text { O PCP se baseia nos } \\
\text { pedidos (fixo para mês } \\
\text { corrente e previsão para de } \\
3 \text { a } 6 \text { meses). }\end{array}$ \\
\hline & Estoque mínimo de 2 dias. & $\begin{array}{l}\text { Estoque mínimo é de } 1,5 \\
\text { dia para produtos nacionais } \\
\text { e } 30 \text { para importados }\end{array}$ & $\begin{array}{l}\text { Empresa trabalha com } \\
2 \text { dias de estoque. }\end{array}$ & Estoque mínimo de 4 dias \\
\hline $\begin{array}{l}\text { Logística dos } \\
\text { materiais }\end{array}$ & $\begin{array}{l}\text { Opera em milk run com a } \\
\text { maioria dos fornecedores, } \\
\text { e uma empresa terceiri- } \\
\text { zada é responsável por } \\
\text { realizá-lo. }\end{array}$ & $\begin{array}{l}\text { Existem fornecedores } \\
\text { dentro da fábrica. } \\
\text { Todas as atividades logísti- } \\
\text { cas são terceirizadas. } \\
\text { Existe centro de consolida- } \\
\text { ção perto de fornecedores } \\
\text { distantes. }\end{array}$ & $\begin{array}{l}\text { Opera em Kanban, com } \\
\text { todo o transporte é realiza- } \\
\text { do por empresa terceira, à } \\
\text { exceção de uma montado- } \\
\text { ra, com quem realiza milk } \\
\text { run. }\end{array}$ & $\begin{array}{l}\text { Opera com Kanban, à ex- } \\
\text { ceção de uma montadora, } \\
\text { com quem opera JIS (Just } \\
\text { In Sequence). } \\
\text { Fornecedores entregam } \\
\text { na empresa, e a empresa } \\
\text { entrega às montadoras. }\end{array}$ \\
\hline
\end{tabular}


variáveis referentes à estrutura das cadeias (clientes, número e porte de fornecedores, componentes terceirizados, critérios de seleção/avaliação e exclusividade de fornecimento,) e às relações entre empresas (existência de contratos, desenvolvimento conjunto e relacionamento com fornecedores não-diretos). Estas informações estão sintetizadas na Tabela 4, de forma a permitir a comparação entre elas nas diversas áreas estudadas.

\section{Análise dos casos}

Com base na análise das prioridades competitivas adotadas pelas empresas, têm-se os primeiros pontos de discussão. Primeiro, as prioridades das montadoras de motores parecem ser extremamente próximas, sendo flexibilidade e custo as dimensões competitivas mais valorizadas por ambas. Entrega, prioridade citada por "A", mas não por "B", também é fortemente condiciona-

Tabela 4. Características relevantes da Gestão da Cadeia de Suprimentos nas empresas.

\begin{tabular}{|c|c|c|c|c|}
\hline & $\begin{array}{c}\text { Montadora de } \\
\text { Motores "A" }\end{array}$ & $\begin{array}{c}\text { Montadora de } \\
\text { Motores "B"' } \\
\end{array}$ & Fornecedor "C'" & Fornecedor "D" \\
\hline Principais clientes & $\begin{array}{l}\text { A montadora de automó- } \\
\text { veis. }\end{array}$ & $\begin{array}{l}\text { As unidades montadoras } \\
\text { de automóveis. }\end{array}$ & $\begin{array}{l}\text { As montadoras de motores } \\
\text { e mercado de reposição }\end{array}$ & $\begin{array}{l}\text { No Brasil, grandes monta- } \\
\text { doras. } \\
60 \% \text { p/ exportação. }\end{array}$ \\
\hline $\begin{array}{l}\text { Número de for- } \\
\text { necedores diretos } \\
\text { (aprox.) }\end{array}$ & $\begin{array}{l}\text { 130. Diversidade de pro- } \\
\text { dutos gerou aumento no } \\
\text { número. }\end{array}$ & $\begin{array}{l}\text { 80. O número diminuiu } \\
\text { nos últimos anos. }\end{array}$ & $\begin{array}{l}80 \text { para as duas plantas do } \\
\text { Brasil. }\end{array}$ & $\begin{array}{l}2 \text { atuais, e um desenvolvido } \\
\text { em stand-by. }\end{array}$ \\
\hline $\begin{array}{l}\text { Porte dos princi- } \\
\text { pais fornecedores }\end{array}$ & $\begin{array}{l}70 \% \text { dos } \\
\text { fornecedores são } \\
\text { de grande porte. }\end{array}$ & $\begin{array}{l}\text { Quase todos os forne- } \\
\text { cedores são de grande } \\
\text { porte. }\end{array}$ & $\begin{array}{l}\text { Grande para aço e fundi- } \\
\text { dos. Menor para minute- } \\
\text { rias. }\end{array}$ & Grande \\
\hline $\begin{array}{l}\text { Fornecedores } \\
\text { exclusivos }\end{array}$ & Não há. & Não há. & $\begin{array}{l}\text { Um fornece, mas há } 3 \text { de- } \\
\text { senvolvidos. }\end{array}$ & Não há. \\
\hline $\begin{array}{l}\text { Componentes } \\
\text { terceirizados }\end{array}$ & $\begin{array}{l}\text { Terceiriza componentes } \\
\text { que não são considerados } \\
\text { tecnologicamente estraté- } \\
\text { gicos. } \\
\text { Faz a usinagem inter- } \\
\text { namente e terceiriza a } \\
\text { fundição. }\end{array}$ & $\begin{array}{l}\text { Terceiriza compo-nentes } \\
\text { que não tecnologica- } \\
\text { mente estratégicos. } \\
\text { Faz internamente a usi- } \\
\text { nagem do bloco motor, } \\
\text { virabrequim e cabeçote. }\end{array}$ & $\begin{array}{l}\text { Terceirizam a produção de } \\
\text { molas. }\end{array}$ & $\begin{array}{l}\text { Terceirizam a produção de } \\
\text { moldes e ferramentaria. }\end{array}$ \\
\hline $\begin{array}{l}\text { Seleção e Avalia- } \\
\text { ção de Fornece- } \\
\text { dores }\end{array}$ & $\begin{array}{l}\text { Custo, capacitação tecno- } \\
\text { lógica e qualidade. }\end{array}$ & $\begin{array}{l}\text { Qualidade, custo, } \\
\text { capacitação } \\
\text { tecnológica e relação } \\
\text { comercial. }\end{array}$ & Custo. & $\begin{array}{l}\text { Qualidade, Custo, } \\
\text { Capacidade e Condição } \\
\text { Financeira. } \\
\text { Exigem sistema de qualida- } \\
\text { de, independente da norma } \\
\text { usada. }\end{array}$ \\
\hline $\begin{array}{l}\text { Contratos com } \\
\text { fornecedores }\end{array}$ & Contratos Informais. & $\begin{array}{l}\text { Contratos formais de um } \\
\text { ano. (renováveis) }\end{array}$ & Contratos formais. & 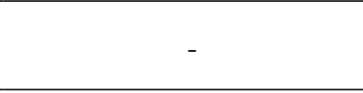 \\
\hline $\begin{array}{l}\text { Desenvolvimento } \\
\text { em conjunto de } \\
\text { produtos } \\
\text { (co-design) }\end{array}$ & $\begin{array}{l}\text { Realiza para alguns com- } \\
\text { ponentes: } \\
\text { - Sistema Blowby (desen- } \\
\text { volvido com um forne- } \\
\text { cedor); } \\
\text { - motor a gás (desenvol- } \\
\text { vido com empresa espe- } \\
\text { cializada); e } \\
\text { - motor bi-combustível } \\
\text { (com fornecedores). }\end{array}$ & $\begin{array}{l}\text { Realiza para alguns } \\
\text { componentes: } \\
\text { - sistemas de injeção } \\
\text { (desenvolvidos com for- } \\
\text { necedores); e } \\
\text { - motor bi-combustível } \\
\text { (desenvolvido com for- } \\
\text { necedores). }\end{array}$ & $\begin{array}{l}\text { Detém a tecnologia de } \\
\text { produto e de processo de } \\
\text { produção de embreagens. } \\
\text { Assim atua em co-desing } \\
\text { com a montadora quando } \\
\text { ocorre necessidade de } \\
\text { desenvolvimentos para } \\
\text { novos motores. }\end{array}$ & $\begin{array}{l}\text { Trabalham em "Enge- } \\
\text { nharia Simultânea" com } \\
\text { os clientes, pois o design } \\
\text { inicial é fornecido por eles, } \\
\text { e refinado em conjunto. }\end{array}$ \\
\hline $\begin{array}{l}\text { Relações com } \\
\text { outros elos da } \\
\text { cadeia de supri- } \\
\text { mentos }\end{array}$ & $\begin{array}{l}\text { A montadora se relaciona } \\
\text { com clientes e fornecedo- } \\
\text { res diretos. } \\
\text { Pode comprar material e } \\
\text { consigná-lo aos fornece- } \\
\text { dores. }\end{array}$ & $\begin{array}{l}\text { A montadora se relacio- } \\
\text { na apenas com clientes e } \\
\text { fornecedores diretos. }\end{array}$ & $\begin{array}{l}\text { Relaciona-se somente com } \\
\text { os fornecedores imediatos. }\end{array}$ & $\begin{array}{l}\text { Relaciona-se somente com } \\
\text { os fornecedores imediatos, } \\
\text { pois os de segunda camada } \\
\text { são muito maiores que a } \\
\text { empresa. }\end{array}$ \\
\hline
\end{tabular}


da pelo aspecto da flexibilidade, uma vez que ambas as empresas estão inseridas em um mercado extremamente dinâmico.

Algumas diferenças podem ser notadas na relação entre prioridades competitivas das montadoras e dos fornecedores. Na relação montadora "A" - fornecedor "C", parece haver relação direta entre as prioridades das duas empresas, mas tal fato parece não ser verificado na relação montadora "B" - fornecedor "D". Esta diferença entre prioridades competitivas pode ser explicada, em parte, pela característica de estabilidade do produto fornecido (não sujeito a drásticas alterações, e de conteúdo tecnológico reduzido) e do seu processo de obtenção, com complexidade relativamente baixa. Além disso, deve-se considerar que os volumes de peças transacionadas entre "A" e "C" são significativamente mais elevados que os volumes envolvidos nas trocas entre "B" e "D".

Ainda relativo às prioridades dos fornecedores, devese ressaltar que ambos mencionam o aspecto da "entrega" como uma das dimensões valorizadas. Tal fato, segundo os entrevistados, é decorrente das pesadas multas impostas pelas montadoras para casos de parada de linha por motivos de falta de componentes.

A qualidade ou não foi citada como prioridade, ou não foi considerada como prioridade máxima, possivelmente devido à percepção de que as empresas constituintes das cadeias automotivas já apresentam "nível satisfatório" de qualidade. Este "nível", compartilhado pela maioria das empresas, é refletido na gestão da qualidade das empresas analisadas, pois estas empresas são certificadas praticamente pelas mesmas normas e adotam ferramentas da qualidade muito próximas umas das outras.

A flexibilidade, aspecto mais valorizado por ambas as montadoras, possui impactos na estrutura e padrão de relacionamento entre as empresas da cadeia de suprimentos. Dada esta necessidade, a escolha estratégica das montadoras foi desenvolver relacionamentos mais estreitos com um menor número de grandes empresas e repassar a busca pela flexibilidade a estes fornecedores.

Além disso, a priorização de custo também possui impacto na escolha realizada pelas empresas quanto ao relacionamento dentro da cadeia. A montadora "A", devido à dimensão competitiva custo, opta também por se relacionar com alguns fornecedores "não imediatos" a fim de utilizar seu maior poder de barganha na compra de materiais que, depois, são repassados a empresas por meio do regime de consignação.

A questão do custo também motivou as montadoras de motores, e até certo ponto os fornecedores, a adotarem práticas de terceirização dos componentes não considerados estratégicos para as empresas. O conteúdo tecnológico é, segundo os entrevistados, um dos critérios-chave para a decisão do que pode ou não ser terceirizado, uma vez que as empresas desejam reduzir custos, mas devem se acautelar do esvaziamento de suas competências.

Vale ressaltar que, na indústria automobilística, a decisão de comprar um determinado componente não necessariamente implica não projetá-lo, já que em determinados casos as montadoras cedem o design dos componentes para que os fornecedores os produzam, assim como ocorre na relação montadora "B" - fornecedor " $D$ ".

A organização do trabalho e a gestão de recursos humanos também possuem papel estratégico relevante nas empresas analisadas. Todas as empresas analisadas adotam arranjo celular na produção, devendo-se destacar que a montadora "A" possui rodízio programado, fato que ocorre (embora não intencionalmente) no fornecedor " $D$ " também. Tal rodízio permite que os funcionários dominem mais etapas do processo produtivo, podendo substituir outros operadores no caso de faltas e, dessa forma, garantir o aspecto de entregas.

Durante a pesquisa, pôde-se verificar que as empresas analisadas possuem estruturas organizacionais enxutas, fato que, além de gerar reduções nos custos fixos, possibilita decisões mais velozes, ampliando flexibilidade e entrega.

A seleção/avaliação dos fornecedores também é fortemente influenciada pelos aspectos competitivos valorizados pela montadora de motores, dado que as competências dos fornecedores têm grande impacto no desempenho desta última. Assim, custo e qualidade estão presentes praticamente nas respostas de todas as empresas, enquanto capacitação tecnológica - fator que fortemente reflete na flexibilidade de produto e processo, além de permitir reduções de custo (Maia e Cerra, 2004b) - é valorizada principalmente pelas montadoras.

O planejamento e controle da produção e a logística também apresentam características que oferecem suporte às prioridades competitivas das empresas. Nas montadoras, previsões revistas semanalmente lhes conferem (que solicitam dos fornecedores) flexibilidade de mix e volume, ao passo que os estoques também garantem certa flexibilidade (proteção contra flutuações de demanda), não onerando muito os custos, por serem reduzidos. Tal fato também se verifica no fornecedor "C", enquanto que no fornecedor " $\mathrm{D}$ " os pedidos são fixos para um mês.

O projeto de sistemas logísticos, além de influenciado pelas prioridades, também é influenciado por questões de localização das empresas. A terceirização, verificada em todas as empresas, conferiu reduções de custo. A montadora "A" opta pelo sistema de milk run, ao passo que a montadora "B", instalada em região de pouca tradição no setor automotivo brasileiro, optou por instalar fornecedores dentro da fábrica e criar um centro de consolidação próximo de vários fornecedores distantes da planta. Nos fornecedores, é interessante destacar a empresa " $D$ ", que opera em "Just In Sequence" com uma das montadoras a que atende. 


\section{Conclusões e considerações finais}

Retomando a primeira questão de pesquisa apresentada, do alinhamento da EO entre as empresas da cadeia, pode-se dizer que existem semelhanças importantes entre as prioridades competitivas dos casos estudados, bem como em suas áreas de decisão estruturais e infra-estruturais.

Especificamente, no tocante às políticas e sistemas infra-estruturais, a semelhança entre as ferramentas de qualidade, formas de organização do trabalho, e abordagens de planejamento da produção/logística, entre outros, pode ser atribuída à grande difusão das técnicas japonesas de administração ("toyotismo"), as quais foram implantadas, sobretudo na indústria automobilística, para impulsionar a competitividade.

As prioridades competitivas das montadoras também apresentam grau significativo de similaridade, indicando que estas necessitam refletir as necessidades do setor industrial no qual tais empresas atuam. Considerando que o maior volume de vendas é dos automóveis considerados "populares", as montadoras enfrentam forte pressão por redução de custos, enquanto que a exigência de ampla diversidade de modelos enfatiza o aspecto "flexibilidade" das operações destas empresas.

No caso das prioridades entre montadoras e fornecedores, também é possível verificar similaridade, fato que corrobora o alinhamento estratégico preconizado pela Gestão da Cadeia de Suprimentos. No entanto, essa similaridade é mais fortemente verificada no conjunto montadora "A" - fornecedor "C" do que no par montadora "B" - fornecedor "D". Este fato sugere que o alinhamento é mediado por fatores como: 1) os próprios aspectos estruturais e relacionais da cadeia, dado que " $\mathrm{C}$ " só fornece para o mercado de reposição de "B", e " $D$ " não fornece para "A"; 2) características dos produtos fornecidos, considerando que "D" não enfatiza flexibilidade, pois produz componentes mais estáveis e de conteúdo tecnológico menor; e 3) o volume de transações que ocorre entre as empresas, menor entre "B" $\mathrm{e}$ " $\mathrm{D}$ ".

Retomando a questão das montadoras, embora haja similitude entre suas prioridades, elas optaram por propostas diferentes de Gestão da Cadeia de Suprimentos para viabilizarem tais prioridades.

Especificamente, no que tange ao custo, a montadora "A" opta por se relacionar com alguns fornecedores "não imediatos", a fim de utilizar seu maior poder de barganha na compra de materiais que, depois, são repassados a empresas de $1^{\circ}$ nível por meio de consignação. Com isso, a empresa consegue reduções de custo agindo diretamente no que seria o fornecedor de segunda camada, caso a cadeia fosse analisada considerando o fluxo de materiais.

Dada a necessidade de flexibilidade, a montadora "A", embora na maior parte dos casos procure manter relações com empresas de maior porte (preferencialmente empresas multinacionais e certificadas em normas de qualidade), procura desenvolver um conjunto maior de empresas pequenas, a fim de torná-las capazes de fornecer os componentes dentro de suas exigências. Em relação a essas empresas menores, a montadora, em um primeiro momento, realiza investimentos consideráveis, mas, posteriormente, passa a ter grande poder para estabelecer preços e volumes de entregas dos componentes. Já a escolha estratégica da montadora "B" foi desenvolver relacionamentos mais estreitos com um número relativamente maior de grandes empresas e repassar-lhes esta busca pela flexibilidade.

Apesar de diferenças quanto ao porte, de forma semelhante, as montadoras atribuem a seus fornecedores de primeira camada a responsabilidade de aumentar a flexibilidade e coordenar tal aumento nas camadas inferiores dos fornecedores, eximindo-se desta coordenação.

Esta escolha corrobora proposição de Alves Filho et al. (2000) que indica que há situações em que nem todos os elos da cadeia precisam ser coordenados, sendo assim necessário determinar quais partes da cadeia merecem maior atenção, de acordo com uma série de fatores como as competências da empresa e o nível de importância de cada subconjunto de peças (e seus correspondentes fornecedores) no contexto de negócio.

A cadeia de suprimentos também influi nas decisões de Estratégia de Operações. No caso da montadora "B", o fato de haver se estabelecido em uma região não tradicional do setor automotivo brasileiro, distante de seus principais fornecedores, obrigou-a a adotar um sistema logístico com lojas dentro das fábricas e com centros de consolidação para o suprimento de autopeças.

O desenvolvimento de produtos também representa ponto de confluência entre a EO e a GCS. No caso das montadoras, estas possuem autonomia diante de suas matrizes internacionais para realizar desenvolvimentos incrementais nos motores e, como resultado de tais desenvolvimentos, buscam parcerias com os fornecedores de suas cadeias para realizar o desenvolvimento conjunto dos componentes necessários. Um exemplo disto é o desenvolvimento de motores bicombustíveis, realizado a partir de motores pré-existentes, mas com o envolvimento dos fornecedores de eletrônicos, com maior expertise nesta área.

Assim, os casos indicam que há influência mútua entre os aspectos estruturais e relacionais das cadeias e as prioridades e decisões da estratégia de operações - remetendo à segunda questão de pesquisa apresentada. Os aspectos concernentes à EO (principalmente as prioridades) parecem afetar o projeto da rede de suprimentos, ao passo que o status quo da estrutura e relações da cadeia condicionam algumas das questões das áreas de decisão da Estratégia de Operações. 
Além disso, este trabalho indica que as montadoras devem exercer influência sobre suas cadeias no que se refere a preço, qualidade, diversidade de produtos e ao conteúdo tecnológico das peças.

Uma das limitações do trabalho aqui apresentado é a base empírica restrita para que se possa fazer recomendações sobre EOs e GCS. Todavia, é importante enfatizar que os estudos de caso realizados nas montadoras de automóveis incluíram questões que envolviam tanto os clientes quanto os fornecedores, de forma a cobrir as cadeias de suprimentos.

Além disso, é necessário ressaltar que o presente trabalho foi pautado em uma visão estratégica de planejamento top-down. Um outro ponto de vista de análise, o de recursos e competências, poderia em trabalho futuro trazer importantes contribuições, analisando como as decisões estratégicas atuais de EO e GCS são influenciadas por competências resultantes de escolhas estratégicas realizadas no passado.

Dada a forte influência mútua entre os fatores de EO e GCS, bem como a dependência de escolhas passadas, são conferidas complexidade e relevância estratégica ainda maior às decisões realizadas em ambas as áreas.

Finalizando, tem-se que os fornecedores principais normalmente atendem a várias montadoras e implementam estratégias que têm de ser compatíveis com a de seus clientes. Dadas as diferentes orientações estratégicas das montadoras, depreende-se a idéia de que devem ser distintas as influências que cada montadora exerce sobre os fornecedores. Neste sentido, fica a proposta de um futuro trabalho para comparar os padrões de relacionamento no caso de determinados fornecedores que simultaneamente servem montadoras distintas, de forma a elucidar em que aspectos particulares a relação é afetada pelas diferentes estratégias adotadas por tais montadoras.

\section{Referências Bibliográficas}

ALVES FILHO, A. G. et al. Automaker Control of the supply chain: the case of Volkswagen's engine plant in São Carlos. In: GERPISA EIGTH INTERNATIONAL COLLOQUIUM, 2000. Proceedings..., Paris, França, 2000.

. Assembler control of the Supply Chain: The case of an engine plant in Brazil. Actes du GERPISA Groupe d'Etudes et de Recherches Permanent sur l' Industrie et les Salariés de l' Automobile, v. 33, n. 1, p. 49-60, Paris 2002.

ALVES FILHO, A. G. et al. O consórcio modular e seus impactos na cadeia de suprimentos da fábrica de motores da VW-São Carlos, Projeto Temático, Processo FAPESP 97/13071-9. Relatório Final, 2001.

ALVES FILHO, A. G.; CERRA, A. L.; MAIA, J. L.; SACOMANO NETO, M.; BONADIO, P. V. G. Pressupostos do Gerenciamento da Cadeia de Suprimentos: evidências de estudos sobre a indústria automobilística. Gestão \& Produção, v. 11, n. 3, p. 275-288, set-dez. 2004.

ASSUMPÇÃO, M. R. P. Reflexão para Gestão Tecnológica em Cadeias de Suprimentos. Gestão \& Produção, v. 10, n. 3, p. 345-362, Dezembro, 2003.

BALLOU, R. H. Business Logistics Management, Planning, Organizing and Controlling the Supply Chain. 4. ed. New Jersey: Prentice Hall, 1999.

BEAMON, B. M. Measuring supply chain performance. International Journal of Operations and Production Management, v. 19, n. 3, p. 275-292, 1999.

BOYER, K. K.; LEWIS, M. W. Competitive priorities: Investigating the need for trade-offs in operations strategy.
Production and Operations Management, v. 11, n. 1, p. 9-20, 2002.

CHOPRA, S.; MEINDL, P. Gerenciamento da Cadeia de Suprimentos, Estratégia, Planejamento e Operação. São Paulo: Prentice Hall, 2003.

CHRISTOPHER, M. Logistics and Supply Chain Management, Strategies for Reducing Cost and Improving Service. 2. ed. London: Prentice Hall, 1998.

COLLIS, D.; MONTGOMERY, C. Competing on Resources: Strategy in the 1990s. Harvard Business Review, p. 118-128, July-August 1995.

COOPER, M. C.; LAMBERT, D. M.; PAGH, J. D. Supply chain management: more than a new name for logistics. International Journal of Logistics Management, v. 8, n. 1, p. 1-13, 1997

DAMME, D. A. V.; ZON, F. L. A. Activity based costing and decision support. International Journal of Logistics Management, v. 10, n. 1, p. 71-82, 1999.

DANGAYACH, G. S.; DESMUKH, S. G. Manufacturing Strategy: Literature review and some issues. International Journal of Operations and Production, v. 21, n. 7, p. 884-932, 2001.

DA SILVEIRA, G.; SLACK, N. Exploring the trade-off concept. International Journal of Operations Management, v. 21, n. 7, p. 949-964, 2001.

DEMETER, K. Manufacturing strategy and competitiveness. International Journal of Production Economics, v. 81-82, p. 205-213, 2003.

FERDOWS, K.; DE MEYER, A. Lasting improvements 
manufacturing performance: in search of a new theory. Journal of Operations Management, v. 9, n. 2, p. 168-194, 1990.

GAGNON, S. Resource-Based Competition and the New Operations Strategy. International Journal of Operations and Production Management, v. 19, n. 2, p. 125-138, 1999.

GARVIN, D. A. Manufacturing Strategy Planning. California Management Review, v. 35, n. 4, p. 85-106, 1993.

GIL, A. C. Métodos e Técnicas de Pesquisa Social. 5. ed. São Paulo: Ed. Atlas, 1999.

HANDFIELD, R. B.; NICHOLS, E. L. Introduction to Supply Chain Management. Saddle River: Prentice Hall, 1999.

HAYES, R.; WHEELWRIGHT, S. C. Restoring our Competitive Edge - Competing through Manufacturing. New York: John Willey \& Sons, 1984.

HAYES, R.; WHEELWRIGHT, S. C.; CLARK, K. B. Dynamic Manufacturing, Creating the Learning Organization. New York: The Free Press, 1988.

HAYES, R. H.; PISANO, G. P.; UPTON, D. M.; WHEELWRIGHT, S. C. Operations, Strategy and Technology, Pursuing the Competitive Edge. New York: John Willey \& Sons, 2004.

HAYES, R. H.; PISANO, G. P. Beyond World-Class: The New Manufacturing Strategy. Harvard Business Review, p. 77-86, January-February 1994.

HAYES, R.; PISANO, G. P. Manufacturing Strategy : At the Intersection of Two Paradigm Shifts. Production and Operations Management, v. 5, n. 1, p. 25-41, 1996.

HILL, T. Operations Management: Strategic Context and Managerial Analysis. Great Britain: Macmillan Ltd., 2000.

HUMPHREY, J.; SALERNO, M. S. Globalization and assembler-supplier relations: Brazil and India. In: HUMPHREY, J.; LECLER, Y.; SALERNO, M. S. (edts.) Global Strategies and Local Realities: The Auto Industry in Emerging Markets. (in association with GERPISAResseau International) London: Macmillan Press Ltd., 2000.

KATHURIA, R. Competitive priorities and managerial performance: a taxonomy of small manufacturers. Journal of Operations Management, v. 18, p. 627-641, 2000.

LAZZARINI, S. G. Estudos de caso: aplicações e limites do método. In: FARINA, E. Estudos de caso em agribusiness, São Paulo: Pioneira, 1997.

LOWSON, R. H. The nature of an operations strategy: combining strategic decisions from the resource-based and market-driven viewpoints. Management Decision, v. 41, n. 6, p. 538-549, 2003.

LUMUS, R. R.; VOKURKA, R. J.; ALBER, K. L. Strategic supply chain planning. Production and Inventory Management Journal, v. 39, p. 49-58, 1998.

MAIA, J. L.; CERRA, A. L. Relacionamento entre empresas na cadeia de uma montadora de motores: uma análise a partir da Economia de Custos de Transação. In: SIMPEP - SIMPÓSIO DE ENGENHARIA DE PRODUÇÃO. 11. 2004. Anais... Bauru/SP, 2004a. Disponível em: <www. simpep.feb.unesp.br>.

Estratégia de Produção e Estratégia Tecnológica em uma montadora de motores p/ automóveis. In: SEGET - SIMPÓSIO DE EXCELÊNCIA EM GESTÃO. Anais... Resende/RJ, 2004b. CD-ROM.

MCHUG, M.; HUMPHREYS, P.; MCIVOR, R. Buyersupplier relationships and organizational health. The Journal of Supply Chain Management, p. 15-25, May, 2003.

NOGUEIRA, E. Empresas Fabricantes de Revestimentos Cerâmicos e a Gestão de seus Sistemas Produtivos. A Proposição de um Modelo. Tese (Doutorado em Administração de Empresas), FGV/EAESP. São Paulo. 2002.

OLIVEIRA, D. P. R. Planejamento Estratégico, Conceitos, metodologias e práticas. 10. ed. São Paulo: Atlas, 2001.

PEDROSO, M. C. Um estudo sobre o desenvolvimento de competências em Gestão de Cadeia de Suprimentos. Tese (Doutorado em Engenharia de Produção) - Escola Politécnica, Universidade de São Paulo. São Paulo, 2002.

PIRES, S. R. I. Managerial implications of the modular consortium in a Brazilian automotive plant. Int. Journal of Operations \& Production Management, v. 18, n. 3, p. 221-232, 1998.

. Supply Chain Management. 2001. Disponível em: $<$ http://www.numa.org.br> Acesso em: junho de 2001.

POSTHUMA, A. C. Autopeças na encruzilhada: modernização desarticulada e desnacionalização. In: ARBIX, G.; ZILBOVICIUS, M. (orgs.). De JK a FHC: a reinvenção dos carros. São Paulo: Scritta, 1997.

RAMDAS, D. F.; SPERKMAN, R. E. Chain or shackles: understanding what drives supply-chain performance. Interfaces, v. 30, n. 4, p. 3-31, 2000.

RICHARDSON, R. J. Pesquisa Social, método e técnicas. São Paulo: Atlas, 1985.

SALERNO, M. S.; MARX, R.; ZILBOVICIUS, M. A nova configuração da cadeia de fornecimento na indústria automobilística do Brasil. Revista de Administração da USP, v. 38, n. 3, p. 192-204, 2003. 
SCHROEDER, R. G., BATES, K. A.; JUNTTILA, M. A. A Resource-Based View of Manufacturing Strategy and the Relationship to Manufacturing Performance. Strategic Management Journal, v. 23, p. 105-117, 2002.

SKINNER, W. Manufacturing - Missing Link in Corporate Strategy. Harvard Business Review, v. 47, n. 3, 1969.

SLACK, N.; CHAMBERS, S.; JOHNSTON, R. Administração da Produção. 2. ed. São Paulo: Atlas, 2002.
TAN, K. C. Supply Chain Management: Practices, concerns, and performance issues. The Journal of Supply Chain Management, p. 42-53, Winter, 2002.

YIN, R. K. Case Study Research, Design and Methods. 2. ed. London: Sage, 1994.

WARD, P. T.; DURAY, R. Manufacturing Strategy in Context: Environment, competitive strategy and manufacturing strategy. Journal of Operations Management, v. 18, n. 2 , p. $123-138,2000$.

\title{
INTERRELATIONSHIP BETWEEN OPERATIONS STRATEGY AND SUPPLY CHAIN MANAGEMENT: CASE STUDIES IN THE AUTOMOTIVE ENGINE SECTOR
}

\begin{abstract}
The worldwide automotive industry has undergone major changes in recent years. In Brazil, the establishment of new automakers, the consolidation and denationalization of autoparts, and the introduction of low displacement engines and bi-fuelled engines have important strategic implications for these companies and for their supply chains. Based on these implications, this paper attempts to shed light on the interrelationship between Operations Strategy $(O S s)$ and Supply Chain Management (SCM), analyzing case studies conducted at two engine manufacturers in Brazil and at two of their suppliers. The findings of these case studies indicate strong interrelationships between competitive priorities and decisions involving structural and infrastructural issues, and between the structural and relational aspects of the productive chains to which these companies belong. The automakers studied here have similar OSs, but their priorities and actions take place within the contexts of different supply chain structures and, hence, are governed by distinct forms of relationships. Given the mutual influence of OS and SCM factors and the dependence on previous strategic choices, the decisions made in these two areas are even more complex and strategically relevant.
\end{abstract}

Keywords: operations strategy, supply chain management, Brazilian automotive industry. 